\title{
Taxonomy of prokaryotic viruses: 2018-2019 update from the ICTV Bacterial and Archaeal Viruses Subcommittee
}

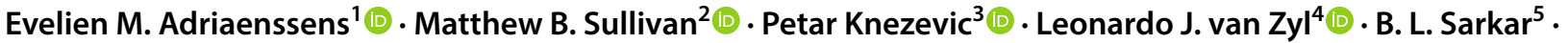

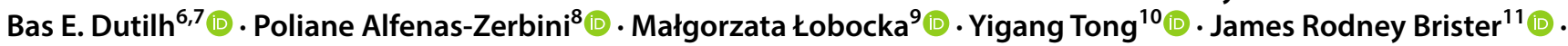

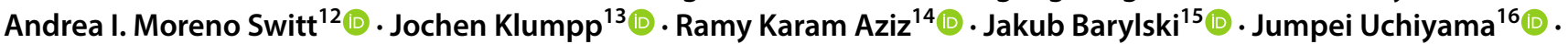 \\ Rob A. Edwards ${ }^{17,18}$ (1) Andrew M. Kropinski ${ }^{19,20}$ - Nicola K. Petty ${ }^{21}$ - Martha R. J. Clokie ${ }^{22}$ - Alla I. Kushkina ${ }^{23}$ (D)

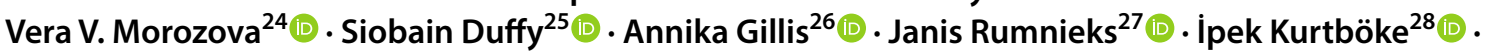 \\ Nina Chanishvili ${ }^{29}$ (D) Lawrence Goodridge ${ }^{19}$ (D) Johannes Wittmann ${ }^{30}$ (1) $\cdot$ Rob Lavigne $^{31}$ (1) $\cdot$ Ho Bin Jang ${ }^{32}$ (1)

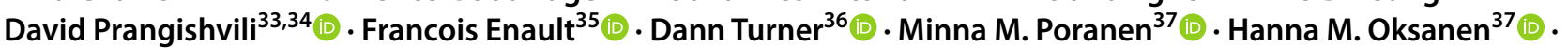 \\ Mart Krupovic $^{33}$
}

Published online: 11 March 2020

(c) Springer-Verlag GmbH Austria, part of Springer Nature 2020

\begin{abstract}
This article is a summary of the activities of the ICTV's Bacterial and Archaeal Viruses Subcommittee for the years 2018 and 2019. Highlights include the creation of a new order, 10 families, 22 subfamilies, 424 genera and 964 species. Some of our concerns about the ICTV's ability to adjust to and incorporate new DNA- and protein-based taxonomic tools are discussed.
\end{abstract}

\section{Introduction}

The prokaryotic virus community is represented in the International Committee on Taxonomy of Viruses (ICTV) by the Bacterial and Archaeal Viruses Subcommittee. Since our last report [1], the committee composition has changed, and over 200 taxonomic proposals (TaxoProps) were submitted to the ICTV Executive Committee (EC) for evaluation and approval. Below, we summarize these new developments.

\section{Changes in subcommittee membership}

In an effort to increase the geographical diversity of members, we appointed representatives from Australia (İ. Kurtböke), Canada (L. Goodridge), Georgia (N. Chanishvili), India (B.L. Sarkar), Russia (V.V. Morozova) and Ukraine (A. Kushkina). Lamentably, Nicola Petty has had to withdraw from our committee.

Handling Editor: Sead Sabanadzovic.

Extended author information available on the last page of the article

\section{Taxonomic updates}

Over the past two years, our subcommittee has proposed the creation of a new order (Tubulavirales), ten new families (Autographiviridae, Chaseviridae, Demerecviridae, Drexlerviridae, Finnlakeviridae, Halspiviridae, Herelleviridae, Ovaliviridae, Plectroviridae, Thaspiviridae), 22 new subfamilies, 424 new genera and 964 new species. In previous versions of this update, we listed each of the new taxa, but this is not practical with the introduction of almost 500 new genera. Instead, we briefly introduce the new order and each of the new families below.

\section{Tubulavirales}

The new bacteriophage order Tubulavirales comprises the rearranged family Inoviridae (five existing genera and 18 new genera) and the new family Plectroviridae (two existing genera and one new genus). The members of the order Tubulavirales possess $(+)$ ssDNA genomes and have a unique morphology, visible as flexible filaments or rigid rods, due to helical symmetry of the capsid. This combination of particle morphology and genome type is unique among viruses, with the exception of representatives of archaeal viruses from the family Spiraviridae, which, however, are substantially different in virion organization and gene content [2]. The 
genomes of the new order members contain from 4 to 15 ORFs and are similarly organized, with a modular organization. These phages infect Gram-positive, Gram-negative or cell-wall-less bacteria. A prominent characteristic of this order is that its member viruses enter neither typical lytic nor lysogenic cycles. Instead, virions are released from cells by extrusion, causing a chronic infection without killing the host. The phages belonging to the rearranged family Inoviridae infect Gram-negative and Gram-positive bacteria, and virions appear as long and flexible filaments. The members of the new family Plectroviridae, previously classified as members of the family Inoviridae, infect cell-wall-less bacteria and exhibit the morphology of rigid rods.

\section{Autographiviridae}

In 2008, Lavigne et al. [3] re-examined the taxonomy of the family Podoviridae and, based on shared protein homologs, defined three genera of T7-like phages within a single subfamily, the Autographivirinae. The defining characteristic of the subfamily was the presence of a virion-encoded RNA polymerase (RNAP) from which the subfamily derived its name; "auto" and "graphein" derived from the Greek, meaning "self-writing" or "self-transcribing". The defining morphological characteristics of all these viruses is that they possess a small (ca. $60 \mathrm{~nm}$ in diameter) isometric head attached to a short tail. Their genomes are composed of a linear terminally redundant dsDNA of approximately $41 \mathrm{~kb}$, and all encode a large (>100 kDa) single-subunit RNA polymerase, which is responsible for middle and late transcription. Further common characteristics of these phages include conservation of gene arrangement and apparently genus-specific lysis cassettes and RNAP specificity loops. A new analysis of these viruses reveals nine subfamilies and 132 genera whose members infect bacteria of the classes Betaproteobacteria and Gammaproteobacteria, and the phylum Cyanobacteria. Many of the genera are undersampled and further analyses are required to demonstrate that the new family is not polyphyletic. It is anticipated that further revisions will be necessary in the future.

\section{Chaseviridae}

This taxon is named in honour of Martha Cowles Chase (1927-2003), who, together with Alfred Hershey, experimentally demonstrated that DNA rather than protein is the genetic material. The first isolated phage of this type is $\varphi$ EcoM-GJ1 $[4,5]$. Members of this family are myoviruses with isometric heads $\sim 62 \mathrm{~nm}$ in diameter and contractile tails $\sim 120 \mathrm{~nm}$ in length. The hosts belong to the genera Escherichia, Erwinia, Pectobacterium, Shewanella and Aeromonas, all members of the class Gammaproteobacteria. The genomes possess $\sim 2600$-bp direct terminal repeats, are on average $54.2 \mathrm{kbp}(46.5 \mathrm{~mol} \% \mathrm{G}+\mathrm{C})$ in length and encode about 77 proteins and, in some cases, a tRNA. Except where we have identified genera with two species, this group as a whole displays very little overall DNA sequence relatedness, presumably because the GC-content varies from 43.6 to $52.8 \mathrm{~mol} \%$. At the protein level, Erwinia phage $\mathrm{vB}_{-}$ EamM-Y2 and Shewanella phage SppYZU05 share 34.8\% homologs. Common proteins include the RNA polymerase, DNA polymerase, primase and exonuclease. vConTACT 2.0 $[6,7]$ clusters Aeromonas phage pAh6-C, Escherichia phage phiEcoM-GJ1, Erwinia phage vB_EamM-Y2, Pectobacterium phage PM1, and Shewanella phage Spp001 into one cluster (VC 244_0). Our analysis suggests the presence of two subfamilies: one including the genera Loessnervirus, Suwonvirus, Carltongylesvirus and Faunusvirus, and the other including the genera Yushanvirus and Pahsextavirus.

\section{Demerecviridae}

This new family contains three new subfamilies (Markadamsvirinae [including the genera Tequinavirus, Epsteptimavirus, and Haartmanvirus]; Mccorquodalevirinae [including the genera Myunavirus and Hongcheonvirus]; and Ermolyevavirinae [including the genera Cetovirus, Vipunavirus, and Suttonboningtonvirus]. The hosts for these phages are Aeromonas, Escherichia, Klebsiella, Pectobacterium, Proteus, Providencia, Salmonella, Shigella, Vibrio, and Yersinia species. The genome of coliphage T5 (AY543070.1) is $121.75 \mathrm{kbp}$ in length, with a mol\%GC content of 39.3 and encodes 162 proteins and 24 tRNAs. It is characterized by long $(10,219-b p)$ direct terminal repeats. The average length of the genomes ranges from 106.2 to $122.8 \mathrm{kbp}$, but in most cases no evidence has been presented for terminal redundancy. The average mol\% GC content varies from 39.1 to 45.2. This new family is named in honour of Milislav Demerec (1895-1966), the Croatian-American geneticist who pioneered the work on bacteriophages, and who, together with the Italian-American physicist Ugo Fano (1912-2001), first isolated E. coli phage T5 in 1945 from a mixture provided to them by Tony L. Rakieten (Long Island College of Medicine, USA).

\section{Drexlerviridae}

When originally proposed in 1996, the "T1-like phages" included a single species, Enterobacteria phage T1. Since that time, numerous taxonomic changes have been introduced, with the genus name changing to "Tllikevirus" to "Tunalikevirus" to "Tlvirus" and ultimately to "Tunavirus". In 2015, the subfamily Tunavirinae was introduced, consisting of five genera: Kp36virus, Rogue1virus, Rtpvirus, T1virus and Tlsvirus [8]. In 2018, three additional genera were included: Eclunavirus, Hanrivervirus and Sertoctavirus, 
and the genera Roguelvirus, Tlvirus and Kp36virus were renamed Rogunavirus, Tunavirus and Webervirus, respectively. In total, 31 species have been classified. GenBank now contains the genome sequences of $84 \mathrm{~T} 1$ related phages, calling for re-examination of the relationships within the subfamily. The hosts belong predominantly to the genus Escherichia, but Cronobacter-, Enterobacter-, Klebsiella-, Pantoea- and Shigella-specific isolates have been isolated and sequenced as well. These hosts are all members of the class Gammaproteobacteria. The phage genomes are on average $48.9 \mathrm{kbp}$ long $(46.0 \mathrm{~mol} \% \mathrm{G}+\mathrm{C})$ and encode about 79 proteins and 0-2 tRNAs. This resulted in the addition of 12 new genera and three new subfamilies (Tempevirinae [including the genera Tlsvirus, Hanrivervirus, and Warwickvirus], Rogunavirinae [including the genera Rogunavirus, Eastlansingvirus, Wilsonroadvirus, and Lindendrivevirus], and Braunvirinae [including the genera Rtpvirus, Shandongvirus, Loudonvirus, and Guelphvirus]. This family is named in honour of Henry Drexler, who pioneered research on phage $\mathrm{T} 1$.

\section{Finnlakeviridae}

This new taxon was created for the new "Finnish lake" virus species Flavobacterium virus FLiP (in the new genus Finnlakevirus). FLiP is the sole member of this family and is the only known icosahedral single-stranded (ss) DNA bacteriophage with an internal membrane. FLiP and its host bacterium Flavobacterium sp. strain B330 were isolated from a boreal lake, Lake Jyväsjärvi, Jyväskylä, Finland [9]. The FLiP genome is a circular ssDNA molecule of 9,174 nucleotides. Nine of the 16 open reading frames have no significant sequence identity to other sequences in the databases. The diameter of the virion is $59 \mathrm{~nm}$, and the vertices have elongated spike structures. The capsid $(\mathrm{T}=21)$ is formed by trimeric major capsid proteins with a double $\beta$-barrel fold. Network analysis of the major capsid protein sequences has shown that FLiP forms its own group among the bacterial and archaeal icosahedral viruses and related proviruses [10].

\section{Halspiviridae}

The spindle-shaped virus His 1 has a linear double-stranded DNA genome of 14,464 bp with terminal inverted repeats and encodes a protein-primed family B DNA polymerase [11]. His1 infects the halophilic archaeon Haloarcula hispanica (phylum Euryarchaeota) [12] and was originally classified as a member of the unassigned genus Salterprovirus [11]. The major capsid protein of His 1 shows sequence similarity to those of members of the family Fuselloviridae, which infect hyperthermophilic acidophiles of the order Sulfolobales (phylum Crenarchaeota) [13, 14]. However, unlike His1, fuselloviruses have circular dsDNA genomes and do not encode their own DNA polymerases. Because His1 is sufficiently distinct from all other known cultured viruses, the genus Salterprovirus has been assigned to a separate new family, the Halspiviridae (hal- for halophilic, spi- for spindle-shaped). Furthermore, the species His 1 virus has been renamed "Salterprovirus Hisl".

\section{Herelleviridae}

The family Herelleviridae was named after Félix d'Hérelle, celebrating the 100th anniversary of his discovery of bacteriophages [15]. Members of this family are large myoviruses with a virulent lifestyle that infect bacteria of the phylum Firmicutes. The family was extended from the subfamily Spounavirinae, with Bacillus phage SPO1 being the type member [16], and includes four other subfamilies: Jasinkavirinae, Brockvirinae, Bastillevirinae and Twortvirinae. All members of the family Herelleviridae share a set of core genes, including the terminase large subunit, major capsid protein, tail tube, tail sheath, and tail tape measure protein. They form a monophyletic clade within the tailed phages when using single and concatenated marker gene phylogenies [15], as well as when using GRAViTy [17], vConTACT2 [6], and the phage proteomic tree approach [18]. Members of the same genus in this family share at least $50 \%$ nucleotide sequence identity over the entire genome, whereas members of the same subfamily share at least $25 \%$ translated genome sequence identity as determined with tBLASTx.

\section{Ovaliviridae}

The new family Ovaliviridae (from the Latin ovalis, for oval) is represented by Sulfolobus ellipsoid virus 1 (SEV1) [19], which harbors a linear double-stranded DNA genome of 23,219 bp and encodes 38 predicted proteins, most of which have no known function. SEV1 has been classified as the first representative of a new family because of its unique morphology, unusual architecture of the virion, and lack of gene content similarity to other characterized viruses. The virion of SEV1 contains a protein capsid with 16 regularly spaced striations and an 11-nm-thick envelope [19]. The virus acquires its envelope intracellularly and exits the host cell through hexagonal pyramidal portals that perforate the host cell envelope.

Sulfolobus ellipsoid virus 1 is designated as the type species of the genus Alphaovalivirus. 


\section{Thaspiviridae}

The virions of Nitrosopumilus spindle-shaped virus 1 (NSV1) measure $64 \pm 3 \mathrm{~nm}$ in diameter and $112 \pm 6 \mathrm{~nm}$ in length, with a short tail at one pole [20]. This morphology is similar to that of fuselloviruses and the halspivirus His1 [13]. The genome of NSV1 is a linear dsDNA molecule of $27,548 \mathrm{bp}$, terminating with 176-bp-long inverted repeats. NSV1 encodes 48 predicted proteins, only one of which (protein-primed family B DNA polymerase) displays significant sequence similarity to the proteins of other known archaeal or bacterial viruses. NSV1 is the first and, thus far, the only virus isolated on ammonia-oxidising archaea of the phylum Thaumarchaeota [20]. NSV1 has been classified into the species Nitmarvirus NSVI within the genus Nitmarvirus (for Nitrosopumilus maritimus virus) and the new family Thaspiviridae (Tha- for thaumarchaeal, spi- for spindle-shaped viruses).

\section{Online (10th) Report of the ICTV}

Virus Taxonomy: The Classification and Nomenclature of Viruses - The Online (10th) Report of the ICTV is freely accessible at http://ictv.global/report, and summaries of the chapters on each virus family are published in the Journal of General Virology. We would like to acknowledge the hard work of David Prangishvili and Mart Krupovic for contributing chapters on archaeal (Ampullaviridae [21], Bicaudaviridae [22], Globuloviridae [23], Guttaviridae [24], Spiraviridae [25], Tristromaviridae [26], and bacterial (Plasmaviridae [27]) viruses.

\section{Final thoughts from the Chair, Professor Andrew Kropinski}

I would hazard a guess that the Bacterial and Archaeal Viruses Subcommittee (BAVS) has changed the taxonomy of the viruses that are their responsibility over the past five years more than any other group within the ICTV at any point in history. This has resulted in a taxonomy which is much closer aligned to that of other viruses than ever before. To indicate how phage taxonomy has changed: In 2014, within the order Caudovirales there were three families, six subfamilies, 72 genera and 484 species. There are now 10 families, 35 subfamilies, 672 genera and 1976 species. The pace and volume of taxonomic changes over the last years may have introduced a period of confusion in the scientific literature. This transition period has been unavoidable but will create a more sustainable clarity in the long term. We must do our best to guide the community through this transition period towards 'stable ground', which will in turn enable textbooks, education tools, databases etc. to follow through.

I would like to thank specifically four individuals: Hans Ackermann (aka Dr. Phage Electron Microscopy/ Dr. Comma), who in spite of misgivings about the direction that we were taking, was always supportive. Whenever I look at an electron micrograph of a phage, I ask myself "What would Hans think of this?" He is greatly missed. Jens Kuhn, who taught me what a taxon is, and who was always ready to support us and write long explanatory emails on the finer aspects of taxonomy, in spite of an extremely busy schedule. Igor Tolstoy from NCBI, who appears to operate without sleep and who sends me queries on deposited phage genomes which have enhanced our taxonomy. Evelien Adriaenssens, who became involved in phage taxonomy with me in 2012, and without whom we would have been far less productive. I know that our subcommittee will be in excellent hands when she takes over its leadership this year.

\section{Future directions}

In 2019, it was proposed to the ICTV Executive Committee that the Bacterial and Archaeal Viruses Subcommittee be split. This would result in the formation of the Archaeal Viruses Subcommittee and the Bacterial Viruses Subcommittee.

There is a movement within the ICTV towards a binomial system of viral nomenclature [28]. We therefore request that the phage community move away from giving their isolates names such as "Escherichia phage XYZ2020" and instead use a format similar to "Escherichia phage Fuddleduddle." Using words (sensical or not) instead of an alphanumerics will facilitate the expected move to a Linnaean-like system for species names (i.e., if "Escherichia phage Fuddleduddle" is a member of the genus "Twaddlevirus", then the new species for "Escherichia phage Fuddleduddle" could be called "Twaddlevirus fuddleduddle" (with apologies to Pierre Elliot Trudeau). Such a species name, I (AMK) believe, would be more acceptable to the bacteriophage community than the latinate "Twaddlevirus fuddleduddlensis". This naming scheme also has the added benefit that it retains name recognition and better describes the isolate. In GenBank there are currently 426 complete genome sequences for "Escherichia phages", which belong to numerous different families and genera; therefore, the prefix "Escherichia virus" has little additional utility in viral taxonomy. Furthermore, in the case of most virome-derived sequences, we do not know the host bacterium; therefore, the current-species naming convention (host name + virus + species name) will not work. 
We have reached a stage where we need to see fundamental changes in the way Taxonomic Proposals are prepared and assessed. Every year, 400-600 complete phage genome sequences are deposited in the GenBank database, and it has become impossible to rapidly assess potentially new taxa, particularly if they contain numerous representatives. In simple terms, our current way to doing things is too complex and time-consuming. We need to take advantage of the bioinformatically competent ICTV members to develop and implement automated procedures for identification of virus isolates and their easy classification into species, genera, etc. and to generate appropriate documentation. We have recently seen the development of tools such as Pairwise Sequence Comparison (PASC [29]), Sequence Demarcation Tool (SDT [30]), Machine Learning with Digital Signal Processing (ML-DSP [31]), VICTOR [32], ClassiPhage [33], GRAViTy [17], ViPTree [34], vConTACT [6, 7], and the concatenated protein tree method of Low et al. [35], as well as the novel NCBI ORF finder-BLASTp-SymBets; [36] and BLASTN algorithms developed by Igor Tolstoy and Mathew Lueder, respectively. Until such systems are accepted by the ICTV and robust criteria are established to delineate families and subfamilies, phage taxonomy will always lag significantly behind submissions to NCBI, and our committees will not be able to taxonomically address the classification of prophages and metagenomically derived sequences. Environmental virome studies have indicated the existence of huge numbers of diverse and currently unclassified phages, whether it be in oceans, soils or the human gut [37-39]. The case is well illustrated by the families Microviridae and Leviviridae, which have received relatively little attention from the ICTV (i.e., two subfamilies, six genera and 21 species versus two genera and four species, respectively). Environmental studies have indicated that the family Microviridae contains at least five unclassified subfamilies [40-47]. Recently, Callanan et al. [48] predicted 331 species and 247 genera among the single-stranded RNA phages, potentially leading to a significant expansion of the family Leviviridae.

Until such a system is in place, we propose to work closely with NCBI to identify new phage species, genera, and subfamilies and to immediately provide names to NCBI. At the annual EC meeting, complete TaxoProps for the newly identified taxa would be presented to the ICTV.

Acknowledgements The committee would like to thank Dr. Graham Hatfull (University of Pittsburgh) for permitting us to use Actinobacteriophage Database electron micrographs in taxonomy proposals. We would also like to thank Professor Colin Hill (University College Cork, Ireland) for letting us see the preprint of their paper on the diversity of ssRNA phages ahead of its publication.
Funding The views and conclusions contained in this document are those of the authors and should not be interpreted as necessarily representing the official policies of their organizations. E.M.A gratefully acknowledges the support of the UK Biotechnology and Biological Sciences Research Council (BBSRC). This research was funded by the BBSRC Institute Strategic Programme Gut Microbes and Health BB/R012490/1 and its constituent project(s) BBS/E/F/000PR10353. B.E.D. was supported by the Netherlands Organization for Scientific Research (NWO), Vidi Grant 864.14.004. R.A.E was supported by Grant MCB-1330800 from the National Science Foundation. J.R.B. was supported by the Intramural Research Program of the National Institutes of Health, National Library of Medicine. R.L. is a member of the PhageBiotics Research Community, supported by FWO Vlaanderen. M.M.P. was supported by the Academy of Finland (272507). H.M.O. was supported by University of Helsinki funding for InstructF1 research infrastructure.

\section{Compliance with ethical standards}

Conflict of interest The authors declare that they have no conflict of interest.

Ethical approval The authors did not perform any studies with human participants or animals for this article.

\section{References}

1. Adriaenssens EM, Wittmann J, Kuhn JH, Turner D, Sullivan MB, Dutilh BE, Jang HB, van Zyl LJ, Klumpp J, Lobocka M, Moreno Switt AI, Rumnieks J, Edwards RA, Uchiyama J, AlfenasZerbini P, Petty NK, Kropinski AM, Barylski J, Gillis A, Clokie MRC, Prangishvili D, Lavigne R, Aziz RK, Duffy S, Krupovic M, Poranen MM, Knezevic P, Enault F, Tong Y, Oksanen HM, Rodney Brister J (2018) Taxonomy of prokaryotic viruses: 2017 update from the ICTV Bacterial and Archaeal Viruses Subcommittee. Arch Virol 163:1125-1129

2. Mochizuki T, Krupovic M, Pehau-Arnaudet G, Sako Y, Forterre P, Prangishvili D (2012) Archaeal virus with exceptional virion architecture and the largest single-stranded DNA genome. Proc Natl Acad Sci USA 109:13386-13391

3. Lavigne R, Seto D, Mahadevan P, Ackermann H-W, Kropinski AM (2008) Unifying classical and molecular taxonomic classification: analysis of the Podoviridae using BLASTP-based tools. Res Microbiol 159:406-414

4. Jamalludeen N, Johnson RP, Friendship R, Kropinski AM, Lingohr EJ, Gyles CL (2007) Isolation and characterization of nine bacteriophages that lyse O149 enterotoxigenic Escherichia coli. Vet Microbiol 124:47-57

5. Jamalludeen N, Kropinski AM, Johnson RP, Lingohr E, Harel J, Gyles CL (2008) Complete genomic sequence of bacteriophage phiEcoM-GJ1, a novel phage that has myovirus morphology and a podovirus-like RNA polymerase. Appl Environ Microbiol 74:516-525

6. Jang HB, Bolduc B, Zablocki O, Kuhn JH, Roux S, Adriaenssens EM, Brister JR, Kropinski AM, Krupovic M, Lavigne R, Turner D, Sullivan MB (2019) Taxonomic assignment of uncultivated prokaryotic virus genomes is enabled by gene-sharing networks. Nat Biotechnol 37:632-639

7. Bolduc B, Jang HB, Doulcier G, You ZQ, Roux S, Sullivan MB (2017) vConTACT: an iVirus tool to classify double-stranded DNA viruses that infect Archaea and Bacteria. PeerJ 5:e3243 
8. Krupovic M, Dutilh BE, Adriaenssens EM, Wittmann J, Vogensen FK, Sullivan MB, Rumnieks J, Prangishvili D, Lavigne R, Kropinski AM, Klumpp J, Gillis A, Enault F, Edwards RA, Duffy S, Clokie MR, Barylski J, Ackermann HW, Kuhn JH (2016) Taxonomy of prokaryotic viruses: update from the ICTV bacterial and archaeal viruses subcommittee. Arch Virol 161:1095-1099

9. Laanto E, Mantynen S, De Colibus L, Marjakangas J, Gillum A, Stuart DI, Ravantti JJ, Huiskonen JT, Sundberg LR (2017) Virus found in a boreal lake links ssDNA and dsDNA viruses. Proc Natl Acad Sci USA 114:8378-8383

10. Yutin N, Backstrom D, Ettema TJG, Krupovic M, Koonin EV (2018) Vast diversity of prokaryotic virus genomes encoding double jelly-roll major capsid proteins uncovered by genomic and metagenomic sequence analysis. Virol J 15:67

11. Bath C, Cukalac T, Porter K, Dyall-Smith ML (2006) His 1 and His2 are distantly related, spindle-shaped haloviruses belonging to the novel virus group, Salterprovirus. Virology 350:228-239

12. Bath C, Dyall-Smith ML (1998) His1, an archaeal virus of the Fuselloviridae family that infects Haloarcula hispanica. J Virol 72:9392-9395

13. Krupovic M, Quemin ER, Bamford DH, Forterre P, Prangishvili D (2014) Unification of the globally distributed spindle-shaped viruses of the Archaea. J Virol 88:2354-2358

14. Pietilä MK, Atanasova NS, Oksanen HM, Bamford DH (2013) Modified coat protein forms the flexible spindle-shaped virion of haloarchaeal virus His1. Environ Microbiol 15:1674-1686

15. Barylski J, Enault F, Dutilh BE, Schuller MB, Edwards RA, Gillis A, Klumpp J, Knezevic P, Krupovic M, Kuhn JH, Lavigne R, Oksanen HM, Sullivan MB, Jang HB, Simmonds P, Aiewsakun P, Wittmann J, Tolstoy I, Brister JR, Kropinski AM, Adriaenssens EM (2020) Analysis of spounaviruses as a case study for the overdue reclassification of tailed phages. Syst Biol 69:110-123

16. Klumpp J, Lavigne R, Loessner MJ, Ackermann HW (2010) The SPO1-related bacteriophages. Arch Virol 155:1547-1561

17. Aiewsakun P, Simmonds P (2018) The genomic underpinnings of eukaryotic virus taxonomy: creating a sequence-based framework for family-level virus classification. Microbiome 6:38

18. Rohwer F, Edwards R (2002) The phage proteomic tree: a genome-based taxonomy for phage. J Bacteriol 184:4529-4535

19. Wang H, Guo Z, Feng H, Chen Y, Chen X, Li Z, HernandezAscencio W, Dai X, Zhang Z, Zheng X, Mora-Lopez M, Fu Y, Zhang C, Zhu P, Huang L (2018) Novel Sulfolobus virus with an exceptional capsid architecture. J Virol 92:e01717-e01727

20. Kim JG, Kim SJ, Cvirkaite-Krupovic V, Yu WJ, Gwak JH, LopezPerez M, Rodriguez-Valera F, Krupovic M, Cho JC, Rhee SK (2019) Spindle-shaped viruses infect marine ammonia-oxidizing thaumarchaea. Proc Natl Acad Sci USA 116:15645-15650

21. Prangishvili D, Krupovic M, ICTV Report Consortium (2018) ICTV virus taxonomy profile: Ampullaviridae. J Gen Virol 99:288-289

22. Prangishvili D, Krupovic M, ICTV Report Consortium (2018) ICTV virus taxonomy profile: Bicaudaviridae. J Gen Virol 99:864-865

23. Prangishvili D, Krupovic M, ICTV Report Consortium (2018) ICTV Virus Taxonomy Profile: Globuloviridae. J Gen Virol 99:1357-1358

24. Prangishvili D, Mochizuki T, Krupovic M, ICTV Report Consortium (2018) ICTV virus taxonomy profile: Guttaviridae. J Gen Virol 99:290-291

25. Prangishvili D, Mochizuki T, Krupovic M, ICTV Report Consortium (2020) ICTV virus taxonomy profile: Spiraviridae. J Gen Virol. https://doi.org/10.1099/jgv.0.001385
26. Prangishvili D, Rensen E, Mochizuki T, Krupovic M, ICTV Report Consortium (2019) ICTV virus taxonomy profile: Tristromaviridae. J Gen Virol 100:135-136

27. Krupovic M, ICTV Report Consortium (2018) ICTV virus taxonomy profile: Plasmaviridae. J Gen Virol 99:617-618

28. Siddell SG, Walker PJ, Lefkowitz EJ, Mushegian AR, Dutilh BE, Harrach B, Harrison RL, Junglen S, Knowles NJ, Kropinski AM, Krupovic M, Kuhn JH, Nibert ML, Rubino L, Sabanadzovic S, Simmonds P, Varsani A, Zerbini FM, Davison AJ (2019) Binomial nomenclature for virus species: a consultation. Arch Virol. https ://doi.org/10.1007/s00705-019-04477-6

29. Bao Y, Amarasinghe GK, Basler CF, Bavari S, Bukreyev A, Chandran K, Dolnik O, Dye JM, Ebihara H, Formenty P, Hewson R, Kobinger GP, Leroy EM, Muhlberger E, Netesov SV, Patterson JL, Paweska JT, Smither SJ, Takada A, Towner JS, Volchkov VE, Wahl-Jensen V, Kuhn JH (2017) Implementation of objective PASC-derived taxon demarcation criteria for official classification of filoviruses. Viruses 9:106

30. Muhire BM, Varsani A, Martin DP (2014) SDT: a virus classification tool based on pairwise sequence alignment and identity calculation. PLoS One 9:e108277

31. Randhawa GS, Hill KA, Kari L (2019) ML-DSP: machine learning with digital signal processing for ultrafast, accurate, and scalable genome classification at all taxonomic levels. BMC Genom 20:267

32. Meier-Kolthoff JP, Goker M (2017) VICTOR: genome-based phylogeny and classification of prokaryotic viruses. Bioinformatics 33:3396-3404

33. Chibani CM, Farr A, Klama S, Dietrich S, Liesegang H (2019) Classifying the unclassified: a phage classification method. Viruses 11:195

34. Nishimura Y, Yoshida T, Kuronishi M, Uehara H, Ogata H, Goto S (2017) ViPTree: the viral proteomic tree server. Bioinformatics 33:2379-2380

35. Low SJ, Dzunkova M, Chaumeil PA, Parks DH, Hugenholtz P (2019) Evaluation of a concatenated protein phylogeny for classification of tailed double-stranded DNA viruses belonging to the order Caudovirales. Nat Microbiol 4:1306-1315

36. Kristensen DM, Kannan L, Coleman MK, Wolf YI, Sorokin A, Koonin EV, Mushegian A (2010) A low-polynomial algorithm for assembling clusters of orthologous groups from intergenomic symmetric best matches. Bioinformatics 26:1481-1487

37. Paez-Espino D, Eloe-Fadrosh EA, Pavlopoulos GA, Thomas AD, Huntemann M, Mikhailova N, Rubin E, Ivanova NN, Kyrpides NC (2016) Uncovering Earth's virome. Nature 536:425-430

38. Roux S, Brum JR, Dutilh BE, Sunagawa S, Duhaime MB, Loy A, Poulos BT, Solonenko N, Lara E, Poulain J, Pesant S, KandelsLewis S, Dimier C, Picheral M, Searson S, Cruaud C, Alberti A, Duarte CM, Gasol JM, Vaque D, Bork P, Acinas SG, Wincker P, Sullivan MB (2016) Ecogenomics and potential biogeochemical impacts of globally abundant ocean viruses. Nature 537:689-693

39. Shkoporov AN, Clooney AG, Sutton TDS, Ryan FJ, Daly KM, Nolan JA, McDonnell SA, Khokhlova EV, Draper LA, Forde A, Guerin E, Velayudhan V, Ross RP, Hill C (2019) The human gut virome is highly diverse, stable, and individual specific. Cell Host Microbe 26:527-541 (e525)

40. Callanan J, Stockdale SR, Shkoporov A, Draper LA, Ross RP, Hill C (2018) RNA phage biology in a metagenomic era. Viruses 10:386

41. Creasy A, Rosario K, Leigh BA, Dishaw LJ, Breitbart M (2018) Unprecedented Diversity of ssDNA phages from the family Microviridae detected within the gut of a protochordate model organism (Ciona robusta). Viruses 10:404

42. Gong Z, Liang Y, Wang M, Jiang Y, Yang Q, Xia J, Zhou X, You S, Gao C, Wang J, He J, Shao H, McMinn A (2018) Viral diversity 
and its relationship with environmental factors at the surface and deep sea of Prydz Bay, Antarctica. Front Microbiol 9:2981

43. Krishnamurthy SR, Janowski AB, Zhao G, Barouch D, Wang D (2016) Hyperexpansion of RNA bacteriophage diversity. PLoS Biol 14:e1002409

44. Quaiser A, Dufresne A, Ballaud F, Roux S, Zivanovic Y, Colombet J, Sime-Ngando T, Francez AJ (2015) Diversity and comparative genomics of Microviridae in Sphagnum-dominated peatlands. Front Microbiol 6:375

45. Sommers P, Fontenele RS, Kringen T, Kraberger S, Porazinska DL, Darcy JL, Schmidt SK, Varsani A (2019) Single-stranded DNA viruses in antarctic cryoconite holes. Viruses 11:1022
46. Wang H, Ling Y, Shan T, Yang S, Xu H, Deng X, Delwart E, Zhang W (2019) Gut virome of mammals and birds reveals high genetic diversity of the family Microviridae. Virus Evol 5:vez013

47. Zhong X, Guidoni B, Jacas L, Jacquet S (2015) Structure and diversity of ssDNA Microviridae viruses in two peri-alpine lakes (Annecy and Bourget, France). Res Microbiol 166:644-654

48. Callanan J, Stockdale SR, Shkoporov A, Draper LA, Ross RP (2020) Hill C (2020) Expansion of known ssRNA phage genomes: from tens to over a thousand. Sci Adv 6(6):eaay5981. https://doi. org/10.1126/sciadv.aay5981

Publisher's Note Springer Nature remains neutral with regard to jurisdictional claims in published maps and institutional affiliations.

\section{Affiliations}

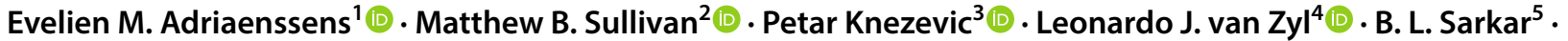

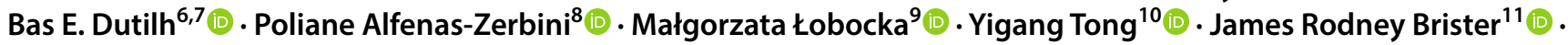

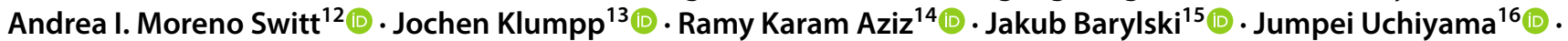
Rob A. Edwards ${ }^{17,18}$ - Andrew M. Kropinski ${ }^{19,20}$ - Nicola K. Petty ${ }^{21}$ (1) Martha R. J. Clokie ${ }^{22}$ - Alla I. Kushkina ${ }^{23}$ (1)

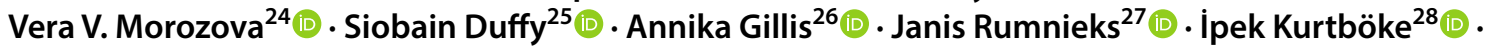

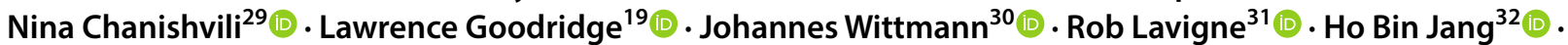
David Prangishvili ${ }^{33,34}$ (D) Francois Enault ${ }^{35}$ (D) - Dann Turner $^{36}$ (D) Minna M. Poranen ${ }^{37}$ (D) Hanna M. Oksanen ${ }^{37}$ (D) Mart Krupovic $^{33}$

Andrew M. Kropinski

Phage.Canada@gmail.com

1 Quadram Institute Bioscience, Norwich Research Park, Norwich, Norfolk NR4 7UQ, UK

2 Department of Microbiology and Civil, Environmental and Geodetic Engineering, The Ohio State University, Columbus, $\mathrm{OH} 43210$, USA

3 Department of Biology and Ecology, Faculty of Sciences, University of Novi Sad, Novi Sad, Serbia

4 Department of Biotechnology, Institute for Microbial Biotechnology and Metagenomics (IMBM), University of the Western Cape, Bellville, Cape Town 7535, South Africa

5 ICMR-National Institute of Cholera and Enteric Diseases, P-33, C.I.T. Road, Scheme XM, Beleghata, Kolkata 700010, India

6 Theoretical Biology and Bioinformatics, Utrecht University, Utrecht, The Netherlands

7 Centre for Molecular and Biomolecular Informatics, Radboud University Medical Centre, Nijmegen, The Netherlands

8 Laboratory of Industrial Microbiology, Instituto de Biotecnologia Aplicada à Agropecuária, Universidade Federal de Viçosa, Viçosa, Minas Gerais, Brazil

9 Department of Microbial Biochemistry, Institute of Biochemistry and Biophysics of the Polish Academy of Sciences, 02-106 Warsaw, Poland

10 College of Life Science and Technology, Beijing University of Chemical Technology, Beijing 100029, China
11 National Center for Biotechnology Information, National Library of Medicine, National Institutes of Health, Bethesda, MD 20894, USA

12 Faculty of Life Sciences, Universidad Andres Bello, Republica 440, 8370146 Santiago, Chile

13 Institute of Food, Nutrition and Health, ETH Zurich, 8092 Zurich, Switzerland

14 Department of Microbiology and Immunology, Faculty of Pharmacy, Cairo University, Qasr El-Ainy St, Cairo 11562, Egypt

15 Department of Molecular Virology, Institute of Experimental Biology, Adam Mickiewicz University, Poznan, Poland

16 School of Veterinary Medicine, Azabu University, Fuchinobe 1-17-71, Chuo-ku, Sagamihara, Kanagawa 252-0206, Japan

17 Department of Computer Science, San Diego State University, San Diego, CA 92182, USA

18 Department of Biology, San Diego State University, San Diego, CA 92182, USA

19 Food Science Department, University of Guelph, 50 Stone Road East, Guelph, ON N1G 2W1, Canada

20 Department of Pathobiology, Ontario Veterinary College, University of Guelph, 50 Stone Road E, Guelph, ON N1G 2W1, Canada

21 The ithree Institute, University of Technology Sydney, Sydney, NSW 2007, Australia

22 Department of Infection, Immunity and Inflammation, University of Leicester, Leicester LE1 9HN, UK

23 Department of Bacteriophage Molecular Genetics, D.K. Zabolotny Institute of Microbiology and Virology, 
the NAS of Ukraine, 154 Acad.Zabolotny str, Kyiv 03143, Ukraine

24 Institute of Chemical Biology and Fundamental Medicine (RAS), Novosibirsk, Russia

25 Department of Ecology, Evolution and Natural Resources, Rutgers University, New Brunswick, NJ 08901, USA

26 Section of Molecular Microbiology and Medical Research Council Centre for Molecular Bacteriology and Infection, Imperial College London, London SW72AZ, UK

27 Latvian Biomedical Research and Study Center, Ratsupites 1, Riga 1067, Latvia

28 Genecology Research Centre, School of Science and Engineering, University of the Sunshine Coast, Maroochydore DC, QLD 4558, Australia

29 G. Eliava Institute of Bacteriophages, Microbiology and Virology, 3 Gotua Street, 0160 Tbilisi, Georgia

30 Leibniz Institute DSMZ-German Collection of Microorganisms and Cell Cultures $\mathrm{GmbH}$, 38124 Brunswick, Germany
31 Laboratory of Gene Technology, Department of Biosystems, KU Leuven, Kasteelpark Arenberg 21 box 2462, 3001 Leuven, Belgium

32 Department of Microbiology, The Ohio State University, Columbus, OH 43210, USA

33 Archaeal Virology Unit, Department of Microbiology, Institut Pasteur, 75015 Paris, France

34 Ivane Javakhishvili Tbilisi State University, 0179 Tbilisi, Georgia

35 Université Clermont Auvergne, CNRS, LMGE, 63000 Clermont-Ferrand, France

36 Faculty of Health and Applied Sciences, University of the West of England, Bristol, Frenchay Campus, Bristol BS16 1QY, UK

37 Molecular and Integrative Biosciences Research Programme, Faculty of Biological and Environmental Sciences, University of Helsinki, Helsinki, Finland 